\title{
PROGNOSTIC VALUE OF SOLUBLE P-SELECTIN LEVELS IN COLORECTAL CANCER
}

Patrizia Ferroni ${ }^{1 *}$, Mario Roselli ${ }^{2}$, Francesca MARtini $^{1}$, Roberta D’Alessandro ${ }^{3}$, Sabrina Mariotti $^{2}$, Stefania Basili $^{4}$, Antonella SpILA ${ }^{3}$, Simona Aloe ${ }^{3}$, Raffaele Palmirotta ${ }^{3}$, Alda MagGini ${ }^{3}$, Girolamo Del Monte ${ }^{2,3}$, Raffaello Mancini ${ }^{5}$, Franco Graziano ${ }^{5}$, Maurizio Cosimelli ${ }^{5}$ and Fiorella GuAdaGni ${ }^{3}$

${ }^{1}$ Department of Experimental Medicine and Pathology, University La Sapienza, Rome, Italy

${ }^{2}$ Clinical Oncology Section, Department of Surgery, University “Tor Vergata”, Rome, Italy

${ }^{3}$ Laboratory of Clinical Pathology, Regina Elena Cancer Institute, Rome, Italy

${ }^{4}$ Department of Medical Therapy, University La Sapienza, Rome, Italy

${ }^{5}$ Department of Surgery, Regina Elena Cancer Institute, Rome, Italy

\begin{abstract}
Measurement of soluble (s) P-selectin levels has been proposed as a diagnostic tool for monitoring the clinical course of human neoplasms. Thus, our study was aimed at analyzing the role of sP-selectin in association with clinicopathological variables in $18 \mathrm{I}$ patients with primary $(n=149)$ or metastatic $(n=32)$ colorectal cancer (CRC), 34 patients with benign diseases and $|8|$ control subjects. The results obtained showed that SP-selectin levels were higher in patients with CRC compared either to patients with benign disease $(p=$ $0.006)$ or controls $(p=0.003)$. No differences were observed between the latter and patients with benign diseases. Increased median sP-selectin levels were significantly associated with the presence of distant metastasis $(68.2 \mathrm{ng} / \mathrm{ml}$ vs. $48.6 \mathrm{ng} / \mathrm{ml}, p=0.002)$. Of interest, carcinoembryonic antigen (CEA) levels were independently associated to SP-selectin (regression coefficient $=0.28, p<0.002$ ). Cox's proportional hazards survival analysis of primary CRC patients demonstrated that beside the stage of disease sP-selectin levels had an independent prognostic role in predicting recurrent disease $(H R=2.22, p=0.019)$ and mortality from CRC $(H R=$ $3.44, p=0.017)$. These results suggest that measurement of plasma sP-selectin might represent a prognostic indicator in the management of patients with CRC.

(c) 2004 Wiley-Liss, Inc.
\end{abstract}

Key words: colorectal cancer; adhesion molecules; platelet activation markers; metastasis; relapse-free survival; overall survival

Blood-borne metastasis is a highly regulated and dynamic process in which cancerous cells separate from a primary tumor, migrate across blood vessel walls into the bloodstream and disperse throughout the body to generate new colonies. During their transit into the circulatory system, tumor cells are exposed to vascular cells such as platelets, endothelial cells and neutrophils, all of which may engage adhesive interactions with tumor cells, thus affecting their survival and extravasation from the vasculature.

Selectins are adhesion molecules that mediate calcium-dependent cell-cell interactions among leukocytes (L-selectin), platelets (P-selectin) and endothelial cells (P- and E-selectin). ${ }^{1}$ It was previously shown that $\mathrm{sP}$-selectin binds to colon carcinoma cell lines and that carcinoma growth and metastasis formation are attenuated in P-selectin-deficient mice. ${ }^{2-5}$ More recently, it has been suggested that platelets and/or endothelial cells might primarily recruit colorectal cancer (CRC) cells through a 2-step, sequential process of adhesive interactions, involving selectins, that shares common features but is distinct from that elaborated for neutrophils. ${ }^{2,6}$ All these findings could explain some of the adhesive events of bloodborne tumor cells reported to occur with platelets, and endothelial cells, which are believed to play a part in modulating some early events in tumor metastases.

Increased expression of P-selectin by vascular endothelial cells has been found in human colon cancer $^{7}$ and has been related to the immune/inflammatory reaction often associated to colorectal carcinoma. Moreover, elevated levels of soluble (s)P-selectin have been found in some human neoplastic disorders, such as lung ${ }^{8}$ and breast cancer, ${ }^{9}$ melanoma ${ }^{10}$ and hematological malignancies, ${ }^{9,11}$ and it has been suggested that measurement of sP-selectin may provide a sensitive tool for monitoring the clinical course of melanoma and lymphoma. ${ }^{10,11}$

To date, no clinical information is available on the behavior of sP-selectin in CRC. sP-selectin basal level in the healthy individual is essentially endothelial cell derived, ${ }^{12}$ but any increase above the basal level has been related to platelet activation. ${ }^{13}$ It is currently recognized that approximately $50 \%$ of all cancer patients display abnormalities of the haemostatic system, including platelet functional abnormalities. ${ }^{14}$ Moreover, we have recently demonstrated that elevated sP-selectin levels are found in approximately $30 \%$ of other cancer patients. ${ }^{15}$ Thus, we assumed that a similar percentage of CRC patients may also have increased levels of this adhesion molecule. In this light, the present study was designed to analyze the behavior of presurgical plasma sP-selectin levels in patients with different stages of CRC compared to patients with benign diseases as well as to control subjects. The concomitant measurement of plasma sE-selectin levels (a marker of endothelial dysfunction) was included as a comparator molecule to assess the platelet origin of sP-selectin. Moreover, a follow-up study of primary CRC patients who underwent surgical resection with curative intent was performed to analyze the possible prognostic value of pre-surgical sP-selectin levels in predicting the diseasefree and overall survival of patients with CRC.

\section{METHODS}

\section{Patients}

Two hundred fifteen patients with either benign $(n=34)$ or malignant $(n=181)$ colorectal diseases, treated at our Institutions, entered into the study. As control group, 181 healthy subjects [122 males, 59 females; mean age $60.2 \pm 13.3$ years, ranging from 33 to 85 years] were also evaluated. The 181 CRC patients [105 males, 76 females; mean age $62.3 \pm 10.6$ years, ranging from 33 to 85 years] were histologically diagnosed with primary $(n=149)$ or metastatic (liver, $n=21$; peritoneum, $n=7$; lung, $\mathrm{n}=1$ and multiple metastasis, $n=3$ ) colorectal adenocarcinoma. Primary CRC was pathologically staged according to the Dukes' classification:

Grant sponsor: P.F. Ministero della Salute; Grant sponsor: CNR-MIUR

*Correspondence to: Department of Experimental Medicine and Pathology, University of Rome La Sapienza, Viale Regina Elena 324, 00161 , Rome, Italy. Fax: +39-06-4454820. E-mail: patrizia.ferroni@uniroma1.it

Received 3 December 2003; Revised 16 January 2004; Accepted 20 January 2004

DOI 10.1002/ijc.20189

Published online 23 April 2004 in Wiley InterScience (www.interscience. wiley.com). 
Stage A $(n=15)$, Stage B $(n=73)$, Stage C $(n=40)$ and Stage D ( $n=21$, with a single resectable liver metastasis). Benign colorectal diseases (18 males, 16 females; mean age $53.4 \pm 13.1$ years, ranging from 34 to 77 years) included polyps $(n=26)$ and chronic ulcerative colitis in stable phase of disease $(n=8)$.

The 149 patients diagnosed with primary CRC ( 86 males, 63 females, mean age $62.5 \pm 10.3$ years) were followed from the time of diagnosis of primary tumor for at least 3 years after surgery. All patients were generally reviewed at 3-month intervals during the first 2 years after surgery. Thereafter, the interval between visits increased to 6 or 12 months in parallel with tumor stage. The study was performed under the appropriate institutional ethics approvals and in accordance with the principles embodied in the Declaration of Helsinki. Written informed consent was obtained from each subject.

\section{Sample collection and immunoassays}

Blood samples from primary CRC patients were drawn within 1 week before surgery, or prior to neoadjuvant chemotherapy and/or irradiation. Samples from patients with metastatic disease were obtained at the time of clinical diagnosis, and prior to any treatment. Serum samples from patients with benign disease were drawn at time of endoscopy. After an overnight fast and a rest of at least $20 \mathrm{~min}$, blood was drawn from each consenting subject by venipuncture of the antecubital vein using a $20 \mathrm{G}$ needle. Blood was then collected into Na citrate $3.8 \%(1: 9, \mathrm{v}: \mathrm{v})$ and immediately centrifuged at $1,500 \mathrm{~g}$ for $15 \mathrm{~min}$ at room temperature. Plasma samples were aliquoted, coded and stored at $-40^{\circ} \mathrm{C}$ until the assays were performed.

sP-selectin and sE-selectin levels were measured by enzymeimmunometric assays (R\&D Systems, Minneapolis, MN) according to the manufacturer's instructions. Intra- and inter-assay coefficients of variation were below $5 \%$ and $10 \%$, respectively, for both assays. The minimum detectable doses for sP-selectin and $\mathrm{sE}$-selectin were $0.5 \mathrm{ng} / \mathrm{ml}$ and $0.1 \mathrm{ng} / \mathrm{ml}$, respectively. The cut-off value for sP-selectin was set at $75 \mathrm{ng} / \mathrm{ml}$ according to the mean value $+2 \mathrm{SD}$ of the levels observed in the 181 control subjects.

Serum carcinoembryonic antigen (CEA) levels were measured using a commercially available immunoassay (Abbott Labs, Chicago, IL). CA 72-4 and CA 19-9 levels were determined using the CA 72-4 DDRIA and the CA 19-9 RIA Kits (both by Fujirebio Diagnostics, Inc., formerly Centocor Diagnostics, Malvern, PA). The cut-off limits chosen for sample evaluation were $5 \mathrm{ng} / \mathrm{ml}, 6$ $\mathrm{U} / \mathrm{ml}$ and $37 \mathrm{U} / \mathrm{ml}$ for CEA, CA 72-4 and CA 19-9, respectively.

Measurements were done blinded. All samples were assayed in duplicate and those showing values above the standard curve were retested with appropriate dilutions.

\section{Statistical analysis}

Sample size of the study was based on the agreement to inclusion criteria and willingness to provide informed consent rather than on sample-size calculations. However, estimation was later performed and suggested that at least 100 patients per group is an appropriate sample size in the case-control study, assuming a $30 \%$ difference in sP-selectin levels between patients and control subjects, using a 2-tailed (alpha) of .05 and 95\% power.

Data are generally presented as percentage of positive patients. Unless otherwise specified, antigen levels are expressed as median and interquartile range (IQR). Statistical analysis was performed by Kruskal-Wallis test followed by Mann-Whitney U test for post-hoc comparison. Differences between percentages were assessed by cross tabulation tables and chi-square analysis. Multiple regression analysis was used to assess the differences and relationships between continuous variables. Univariate and multivariate analyses were performed by Cox's proportional hazard model: the first step was performed by the Log Rank Test and then the covariates found to be associated with the outcome variables were included in the Cox's regression model. For each variable, the proportional hazard has been tested. Clinical and laboratory variables considered in the analysis were age, sex, tumor location, grading, tumor stage, serum tumor markers and plasma sP-selectin levels. The variables that achieved statistical significance in the univariate analysis were subsequently included in a multivariate analysis using a Cox regression model. Only $p$ values lower than 0.05 were regarded as statistically significant. All calculations were made using computer software packages (Statistica 5.5, StatSoft, Inc., Tulsa, OK and EGRET Cytel Software- Co., Cambridge, MA).

\section{RESULTS}

Plasma samples from 396 subjects, including 181 healthy subjects and 215 patients with either malignant $(n=181)$ or benign $(n=34)$ colorectal diseases, were analyzed for the presence of sP-selectin. As shown in Table I, plasma sP-selectin (KruskalWallis test: $\mathrm{H}=12.7, p=0.0018$ ) levels were significantly higher in patients with CRC compared to either controls or patients with benign disease, whereas no difference was observed between the 2 latter groups (Table I). Furthermore, positive sP-selectin levels (above the cutoff value of $75 \mathrm{ng} / \mathrm{ml}$ ) were observed in approximately $21 \%$ of CRC patients compared to $6 \%$ of patients with benign disease and $1 \%$ of control subjects (chi-square $=38.6, p<$ 0.0001 ). No significant differences were observed within the 3 groups with respect to gender and age (data not shown). Plasma sE-selectin levels were higher in CRC patients $(53.3 \pm 28.3 \mathrm{ng} / \mathrm{ml})$ compared to either controls $(34.7 \pm 13.9 \mathrm{ng} / \mathrm{ml}, \mathrm{p}<0.001)$ or patients with benign disease $(33.2 \pm 13.5 \mathrm{ng} / \mathrm{ml}, p<0.001)$, which is in agreement with previously published observations. ${ }^{16}$ As expected, sE-selectin levels did not correlate with sP-selectin levels $\left(\mathrm{R}_{\mathrm{s}}=-0.024, p=0.85\right)$, corroborating the hypothesis of the platelet origin of the latter.

The relationship between plasma $\mathrm{SP}$-selectin and clinical staging of CRC was also evaluated (Table II). As shown, no significant association was found between sP-selectin levels and the stage of disease, but elevated levels of sP-selectin were found in relapsing patients with distant metastasis (Table II). In fact, while approximately $18 \%$ of patients with primary CRC had positive plasma sP-selectin levels, this percentage was doubled in metastatic patients (chi-square $=4.2, p=0.04$ ). Moreover, the median plasma sP-selectin level for metastatic CRC patients was significantly higher than that obtained in patients with primary CRC $(68.2 \mathrm{ng} / \mathrm{ml}$ vs., $48.6 \mathrm{ng} / \mathrm{ml}, p=0.002$ ).

To further analyze the relationship between sP-selectin and clinicopathologic variables of CRC a multiple regression analysis including age, sex, tumor location, grading, stage and tumor marker levels was carried out. The final model obtained by step-

TABLE I - PLASMA SP-SELECTIN LEVELS IN NORMAL INDIVIDUALS AND PATIENTS WITH EITHER BENIGN OR MALIGNANT COLORECTAL DISEASE ${ }^{1}$

\begin{tabular}{|c|c|c|c|c|c|c|c|}
\hline & & \multirow{2}{*}{ Healthy subjects } & \multirow{2}{*}{$p$ value } & \multicolumn{3}{|c|}{ Colorectal diseases } & \multirow{2}{*}{$p$ value $^{2}$} \\
\hline & & & & Benign & $p$ value & Malignant & \\
\hline \multirow[t]{3}{*}{ sP-selectin (ng/ml) } & Mean $\pm \mathrm{SD}$ & $46.7 \pm 14.1$ & & $46.4 \pm 20.7$ & & $62.7 \pm 39.6$ & \\
\hline & Median (IQR) & $47.5(37.0-60.4)$ & $=0.22$ & $42.5(33.2-56.8)$ & $=0.006$ & $50.8(38.3-70.7)$ & $=0.003$ \\
\hline & No. positive $(\%)^{3}$ & $2(1)$ & $=0.06$ & $2(6)$ & $=0.038$ & $38(21)$ & $<0.0001$ \\
\hline
\end{tabular}

\footnotetext{
${ }^{1} p$ values indicate the level of significance obtained for post-hoc analysis performed by Mann Whitney $\mathrm{U}$ test or chi-square analysis. $\mathrm{-}^{2} \mathrm{CRC}$
} vs. healthy subjects. ${ }^{3}$ Number of patients with $\mathrm{sP}$-selectin levels above $75 \mathrm{ng} / \mathrm{ml}$. 
TABLE II - PLASMA SP-SELECTIN AND SERUM TUMOR MARKER LEVELS IN PATIENTS WITH CRC

\begin{tabular}{|c|c|c|c|c|c|c|}
\hline & \multirow{2}{*}{ Number of cases } & \multicolumn{2}{|c|}{ sP-selectin (ng/ml) } & \multirow{2}{*}{$\begin{array}{c}\text { CEA ng/ml } \\
\text { No. positive }(\%)^{2}\end{array}$} & \multirow{2}{*}{$\begin{array}{c}\text { CA } 72-4 \mathrm{U} / \mathrm{ml} \\
\text { No. positive }(\%)^{3}\end{array}$} & \multirow{2}{*}{$\begin{array}{r}\text { CA } 19-9 \mathrm{U} / \mathrm{ml} \\
\text { No. positive }(\%)\end{array}$} \\
\hline & & Mean \pm SD (range) & No. positive $(\%)^{1}$ & & & \\
\hline \multicolumn{7}{|c|}{ Stage of disease } \\
\hline A & 15 & $52.8 \pm 30.8(25.1-149.9)$ & $2(13.3)$ & $2(13.3)$ & $1(6.7)$ & $2(13.3)$ \\
\hline $\mathrm{B}$ & 73 & $60.2 \pm 39.8(21.1-290.3)$ & $12(16.4)$ & $15(20.6)$ & $6(8.2)$ & $4(5.5)$ \\
\hline $\mathrm{C}$ & 40 & $64.7 \pm 43.6(28.2-200.4)$ & $11(27.5)$ & $14(35.0)$ & $8(20.0)$ & $9(22.5)$ \\
\hline $\mathrm{D}$ & 21 & $53.5 \pm 19.1(25.1-108.4)$ & $2(9.5)$ & $11(52.4)$ & $7(33.3)$ & $10(47.6)$ \\
\hline Metastatic & 32 & $76.8 \pm 44.9(30.0-219.1)^{5}$ & $11(34.4)^{6}$ & $24(75.0)^{7}$ & $12(37.5)^{8}$ & $17(53.1)^{7}$ \\
\hline Total & 181 & $62.7 \pm 39.6(21.1-290.3)$ & $38(21.0)$ & $66(36.5)$ & $34(18.8)$ & $42(23.2)$ \\
\hline
\end{tabular}

${ }^{1}$ Number of patients with sP-selectin levels above $75 \mathrm{ng} / \mathrm{ml} ;{ }^{2}$ Number of patients with CEA levels above $5 \mathrm{ng} / \mathrm{ml}$. $-{ }^{3} \mathrm{Number}$ of patients with CA $72-4$ levels above $6 \mathrm{U} / \mathrm{ml} ;{ }^{4}$ Number of patients with CA $19-9$ levels above $37 \mathrm{U} / \mathrm{ml}$. $-{ }^{5}$ Mann Whitney U test primary $v s$. metastatic CRC: $p<0.05$. $-{ }^{6}$ Chi-square analysis between primary and metastatic CRC: $p<0.05$. ${ }^{7}$ Chi-square analysis: $p<0.0001$. $-{ }^{8}$ Chi-square analysis: $p<$ 0.01 .

wise regression analysis revealed that only CEA levels (regression coefficient $=0.28, p=0.0015$ ) were independently related to sP-selectin ( 22 for entire model $=0.10, p=0.004$ ).

Clinical information on postoperative follow-up were available from all primary CRC patients. Over the follow-up period, 94 $(63 \%)$ of the 149 primary CRC patients remained free of disease [median follow-up (range): 49.5 months (36.0-117.7)], while 53 $(36 \%)$ patients experienced relapsing disease [16 local recurrences and 37 distant metastasis, median time to relapse: 14.5 months (1.2-79.7)]. Two (1\%) patients died of nonrelated causes and thus were excluded from all subsequent analyses. No differences were observed in age, sex or site of primary tumor between patients with and without recurrence (data not shown). Presurgical sP-selectin levels were above the cut-off in approximately $28 \%$ of relapsing patients compared to $13 \%(p=0.024)$ of patients who remained free of disease. Moreover, the median presurgical sP-selectin levels increased from $48.4 \mathrm{ng} / \mathrm{ml}$ in patients who remained free of disease and $41.8 \mathrm{ng} / \mathrm{ml}$ in locally relapsing patients to $54.5 \mathrm{ng} / \mathrm{ml}$ in patients who developed distant metastasis $(\mathrm{H}=4.9, p=0.08)$ (Fig. 1). Univariate analysis of clinicopathologic variables and presurgical levels of sP-selectin and tumor markers demonstrated that relapse-free survival was affected by the Dukes' stage of disease $(p<0.001)$ and by pre-surgical levels of plasma sP-selectin $(p=0.034)$ and serum CEA $(p=0.024)$ or CA 19-9 $(p=0.012)$ (Table III). Multivariate analysis obtained by the Cox regression model confirmed the independent prognostic role, in predicting relapsing disease, of stage $(p<0.001)$ and sP-selectin levels $(p=$ 0.019) (Table III)

To further analyze the prognostic value of sP-selectin in CRC a Cox proportional hazards survival analysis of the mortality rates was also performed. As shown in Table IV, Dukes' stage $(p<$

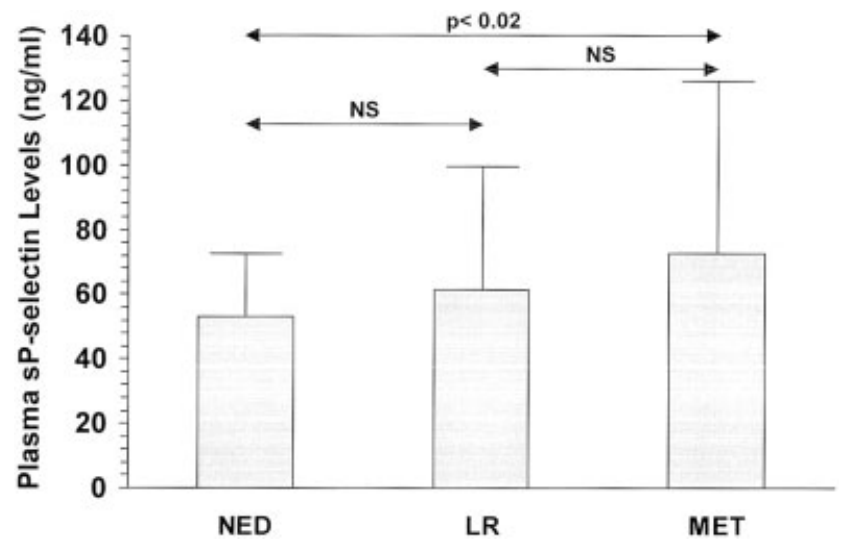

Figure 1 - Presurgical sP-selectin levels in CRC patients who remained free of disease (NED), patients with locoregional recurrence (LR) and patients who developed distant metastasis (MET). Columns indicate mean values; bars indicate standard deviations.
$0.001)$ and presurgical levels of both plasma sP-selectin ( $p=$ $0.017)$ and serum CEA $(p=0.045)$ had an independent prognostic value in predicting mortality (Table IV). Of interest, when a risk-set stratification for the Dukes' stage of disease was applied to the model, only sP-selectin levels (Hazard Ratio $=6.0,95 \%$ C.I.: $1.9-18.5, p=0.002$ ) had an independent prognostic role in predicting mortality. Figure 2 demonstrates the Kaplan-Meier curves for patients with positive (above the cut-off value) or negative (below the cut-off values) sP-selectin levels. As shown, positive presurgical sP-selectin (Log-Rank Statistic $=6.143, p=0.013)$ levels were associated with an increased mortality rate compared to patients with negative levels of this variable.

\section{DISCUSSION}

The results obtained in our study demonstrated for the first time that presurgical sP-selectin levels are increased in patients with $\mathrm{CRC}$ as compared to either control subjects or patients with benign diseases. Nevertheless, sP-selectin levels were not related to tumor location, grading or Dukes' stages but were significantly associated to the presence of distant metastasis. The lack of correlation between sP-selectin and the stage of disease suggests that the increased sP-selectin levels observed in CRC are not due to the tumor itself but are most likely related to the occurrence of in vivo platelet activation, which is in agreement with the current knowledge that any increase of sP-selectin above the basal level is due to platelet activation. ${ }^{13}$ Moreover, the observation that plasma levels of sE-selectin (a well-known marker of endothelial activation) were not correlated with those of sP-selectin in patients with CRC corroborates the hypothesis that the increased levels of sP-selectin found in CRC patients are derived from platelets rather than endothelial cells as a result of in vivo platelet activation. Indeed, subclinical changes in the haemostatic system have been reported in $\mathrm{CRC},{ }^{14,17}$ and a systemic coagulation reactivation has been found in patients with recurrence of CRC previously resected with curative intent. ${ }^{17}$ Thus, it appears conceivable to hypothesize that a subclinical activation of coagulation might be responsible for platelet activation, ${ }^{18}$ with a mechanism similar, at least in part, to that observed in other human diseases. ${ }^{15,19}$

Besides this possible explanation, the occurrence of enhanced sP-selectin levels in CRC might also be justified by the finding here reported that CEA levels were independently related to sPselectin, suggesting that the former might play a direct role in the mechanism(s) inducing sP-selectin elevation in CRC. To date, no information is available whether CEA is capable of directly activating platelets through adhesive interactions. On the other hand, it is well known that CEA is able to induce the synthesis and release of inflammatory cytokines, i.e., interleukin-6 (IL-6), IL-1 $\beta$ and Tumor Necrosis Factor- $\alpha$ (TNF- $\alpha){ }^{20,21}$ All these cytokines may play a pivotal role in the pathogenesis of the prothrombotic state associated to human cancer, probably acting through induction of tissue factor expression by monocytes and/or endothelial cells. $^{22}$ Indeed, CEA-induced IL- $1 \beta$ and TNF- $\alpha$ are responsible for endothelial cell activation and consequent switch to an adhesive 
TABLE III - COX PROPORTIONAL HAZARDS ANALYSIS OF RELAPSE-FREE SURVIVAL IN 147 PRIMARY CRC PATIENTS

\begin{tabular}{|c|c|c|c|c|c|c|c|}
\hline \multirow{2}{*}{ Factors } & \multirow{2}{*}{ Code } & \multirow{2}{*}{$\begin{array}{c}\text { Number of } \\
\text { patients }\end{array}$} & \multirow{2}{*}{$\begin{array}{l}\text { Number of } \\
\text { recurrences }(\%)\end{array}$} & \multicolumn{2}{|c|}{ Univariate } & \multicolumn{2}{|c|}{ Multivariate } \\
\hline & & & & Log-rank chi-square & $p$-value & Hazard ratio (95\% C.I.) & $p$-value \\
\hline \multirow[t]{2}{*}{ Sex } & Females & 62 & $21(34)$ & & & & \\
\hline & Males & 85 & $32(38)$ & 0.007 & NS & & \\
\hline \multirow[t]{3}{*}{ Site } & Colon & 37 & $15(41)$ & & & & \\
\hline & Sigma & 36 & $9(25)$ & & & & \\
\hline & Rectum & 74 & $29(39)$ & 0.056 & NS & & \\
\hline \multirow{4}{*}{ Stage } & A & 15 & $1(7)$ & & & & \\
\hline & $\mathrm{B}$ & 72 & $17(24)$ & & & & \\
\hline & $\mathrm{C}$ & 39 & $22(56)$ & & & & \\
\hline & $\mathrm{D}$ & 21 & $13(62)$ & 24.96 & $<0.001$ & $2.01(1.40-2.88)$ & $<0.001$ \\
\hline \multirow[t]{3}{*}{ Grading } & 1 & 20 & $6(30)$ & & & & \\
\hline & 2 & 92 & $30(33)$ & & & & \\
\hline & 3 & 35 & $17(49)$ & 3.138 & 0.076 & & \\
\hline \multirow[t]{2}{*}{ sP-selectin } & $<75 \mathrm{ng} / \mathrm{ml}$ & 121 & $38(31)$ & & & & \\
\hline & $>75 \mathrm{ng} / \mathrm{ml}$ & 26 & $15(58)$ & 4.471 & 0.034 & $2.22(1.14-4.32)$ & $=0.019$ \\
\hline \multirow[t]{2}{*}{ Serum CEA } & $<5 \mathrm{ng} / \mathrm{ml}$ & 106 & $33(31)$ & & & & \\
\hline & $>5 \mathrm{ng} / \mathrm{ml}$ & 41 & $20(49)$ & 5.085 & 0.024 & $1.52(0.82-2.81)$ & NS \\
\hline \multirow[t]{2}{*}{ Serum CA $72-4$} & $<6 \mathrm{U} / \mathrm{ml}$ & 126 & $43(34)$ & & & & \\
\hline & $>6 \mathrm{U} / \mathrm{ml}$ & 21 & $10(48)$ & 1.895 & NS & & \\
\hline \multirow[t]{2}{*}{ Serum CA 19-9 } & $<37 \mathrm{U} / \mathrm{ml}$ & 122 & $39(32)$ & & & & \\
\hline & $>37 \mathrm{U} / \mathrm{ml}$ & 25 & $14(56)$ & 6.318 & 0.012 & $1.02(0.47-2.22)$ & NS \\
\hline
\end{tabular}

TABLE IV - COX PROPORTIONAL HAZARDS ANALYSIS OF MORTALITY RATES IN 147 PRIMARY CRC PATIENTS

\begin{tabular}{|c|c|c|c|c|c|c|c|}
\hline \multirow{2}{*}{ Factors } & \multirow{2}{*}{ Code } & \multirow{2}{*}{ Number of patients } & \multirow{2}{*}{ Number of death $(\%)$} & \multicolumn{2}{|c|}{ Univariate } & \multicolumn{2}{|c|}{ Multivariate } \\
\hline & & & & Log-rank chi-square & $p$-value & Hazard ratio (95\%C.I.) & $p$-value \\
\hline \multirow[t]{2}{*}{ Sex } & Females & 62 & $10(16)$ & & & & \\
\hline & Males & 85 & $14(17)$ & 0.006 & NS & & \\
\hline \multirow[t]{3}{*}{ Site } & Colon & 37 & $8(22)$ & & & & \\
\hline & Sigma & 36 & $4(11)$ & & & & \\
\hline & Rectum & 74 & $12(16)$ & 0.442 & NS & & \\
\hline \multirow[t]{4}{*}{ Stage } & A & 15 & $0(0)$ & & & & \\
\hline & $\mathrm{B}$ & 72 & $3(4)$ & & & & \\
\hline & $\mathrm{C}$ & 39 & $10(26)$ & & & & \\
\hline & $\mathrm{D}$ & 21 & $11(52)$ & 31.83 & $<0.001$ & $3.65(2.08-6.43)$ & $<0.001$ \\
\hline \multirow[t]{3}{*}{ Grading } & 1 & 20 & $3(15)$ & & & & \\
\hline & 2 & 92 & $12(13)$ & & & & \\
\hline & 3 & 35 & $9(26)$ & 2.001 & NS & & \\
\hline \multirow[t]{2}{*}{ sP-selectin } & $<75 \mathrm{ng} / \mathrm{ml}$ & 121 & $15(12)$ & & & & \\
\hline & $>75 \mathrm{ng} / \mathrm{ml}$ & 26 & $9(35)$ & 6.143 & 0.013 & $3.44(1.24-9.51)$ & $=0.017$ \\
\hline \multirow[t]{2}{*}{ Serum CEA } & $<5 \mathrm{ng} / \mathrm{ml}$ & 106 & $11(10)$ & & & & \\
\hline & $>5 \mathrm{ng} / \mathrm{ml}$ & 41 & $13(32)$ & 10.18 & 0.001 & $2.57(1.02-6.49)$ & $=0.045$ \\
\hline \multirow{2}{*}{ Serum CA 72-4 } & $<6 \mathrm{U} / \mathrm{ml}$ & 126 & $21(17)$ & & & & \\
\hline & $>6 \mathrm{U} / \mathrm{ml}$ & 21 & $3(14)$ & 0.031 & NS & & \\
\hline \multirow[t]{2}{*}{ Serum CA 19-9 } & $<37 \mathrm{U} / \mathrm{ml}$ & 122 & $17(14)$ & & & & \\
\hline & $>37 \mathrm{U} / \mathrm{ml}$ & 25 & $7(28)$ & 3.257 & 0.071 & & \\
\hline
\end{tabular}

phenotype, ${ }^{23,16}$ which is accompanied by a loss of anti-thrombotic properties of the endothelium. All these phenomena may ultimately favor the hematogenous spread of CRC cells.

In this light, the results obtained in the longitudinal study are of interest. To date, no study was specifically conducted to evaluate the prognostic value of sP-selectin in CRC. In our study, a postsurgical follow-up of primary CRC patients was performed to specifically address this issue. It is worth noticing that of the 53 patients who had recurrent disease, $28 \%$ had positive presurgical sP-selectin levels compared to approximately $13 \%$ of patients who remained free of disease. Furthermore, the mean presurgical plasma sP-selectin levels were higher in relapsing patients compared to patients who remained free of disease throughout the follow-up. Positive sP-selectin levels were associated with a worse relapse-free survival and a higher mortality rate when compared to negative cases using univariate analysis. Moreover, Cox's proportional hazards survival analysis confirmed the independent prognostic value of elevated presurgical plasma sP-selectin levels in predicting recurrence as well as mortality from CRC.

In conclusion, we believe that our results support the concept that soluble adhesion molecules may play a pivotal role in the pathogenesis of blood-borne metastasis. We are aware that this

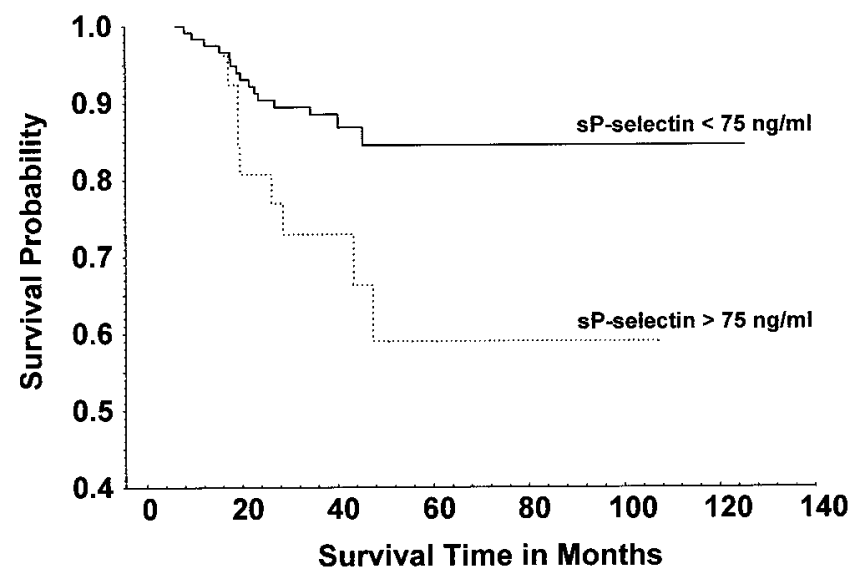

Figure 2 - Kaplan Meier analysis. Comparison between overall survival of patients with either positive (above $75 \mathrm{ng} / \mathrm{ml}$ ) (dotted line) or negative (below $75 \mathrm{ng} / \mathrm{ml}$ ) (solid line) presurgical sP-selectin levels. Log-Rank $=6.143, p<0.02$. 
hypothesis requires detailed experimental evaluation before its ultimate significance can be determined; nevertheless, we hope that our study will prompt investigators to design new studies to better understand the significance of sP-selectin in the disease progression, as well as its contribution as a prognostic factor for CRC. Nonetheless, our results suggest that the determination of plasma levels of sP-selectin might represent a prognostic parameter in the management of patients with CRC and may help in the choice of more aggressive treatment and/or more strict follow-up procedures in a subgroup of patients who are at high risk of recurrence.

\section{ACKNOWLEDGEMENTS}

The authors thank S. Giommi and A. Cialfi for their excellent technical assistance.

\section{REFERENCES}

1. Varki A. Selectin ligands. Proc Natl Acad Sci U S A 1994;91:7390-7.

2. Kim YJ, Borsig L, Han HL, Varki NM, Varki A. Distinct selectin ligands on colon carcinoma mucins can mediate pathological interactions among platelets, leukocytes, and endothelium. Am J Pathol 1999; 155:461-72.

3. Goetz DJ, Ding H, Atkinson WJ, Vachino G, Camphausen RT, Cumming DA, Luscinskas FW. A human colon carcinoma cell line exhibits adhesive interactions with P-selectin under fluid flow via a PSGL-1-independent mechanism. Am J Pathol 1996;149:1661-73.

4. Mannori G, Crottet P, Cecconi O, Hanasaki K, Aruffo A, Nelson RM, Varki A, Bevilacqua MP. Differential colon cancer cell adhesion to E-, P-, and L-selectin: role of mucin-type glycoproteins. Cancer Res $1995 \cdot 55: 4425-31$

5. Aruffo A, Dietsch MT, Wan H, Hellstrom KE, Hellstrom I. Granule membrane protein 140 (GMP140) binds to carcinomas and carcinoma-derived cell lines. Proc Natl Acad Sci U S A 1992;89:2292-6.

6. McCarty OJ, Mousa SA, Bray PF, Konstantopoulos K. Immobilized platelets support human colon carcinoma cell tethering, rolling, and firm adhesion under dynamic flow conditions. Blood 2000;96:178997.

7. Suzuki Y, Ohtani H, Mizoi T, Takeha S, Shiiba K, Matsuno S, Nagura H. Cell adhesion molecule expression by vascular endothelial cells as an immune/inflammatory reaction in human colon carcinoma. Jpn J Cancer Res 1995;86:585-93.

8. Roselli M, Mineo TC, Martini F, Mariotti S, Ambrogi V, Spila A, D'Alessandro R, Basili S, Guadagni F, Ferroni P. Serum Concentrations of soluble selectins in patients with lung cancer. Int $\mathrm{J}$ Biol Markers 2002;17:56-62.

9. Blann AD, Gurney D, Wadley M, Bareford D, Stonelake P, Lip GY. Increased soluble P-selectin in patients with haematological and breast cancer: a comparison with fibrinogen, plasminogen activator inhibitor and von Willebrand factor. Blood Coagul Fibrinolysis 2001; 12:43-50.

10. Schadendorf D, Diehl S, Zuberbier T, Schadendorf C, Henz BM. Quantitative detection of soluble adhesion molecules in sera of melanoma patients correlates with clinical stage. Dermatology 1996;192: 89-93.

11. Haznedaroglu IC, Benekli M, Ozcebe O, Savas MC, Gullu IH, Dundar SV, Kirazli S. Serum L-selectin and P-selectin levels in lymphomas. Haematologia 2000;30:27-30.
12. Burger PC, Wagner DD. Platelet P-selectin facilitates atherosclerotic lesion development. Blood 2003;101:2661-6.

13. Chong BH, Murray B, Berndt MC, Dunlop LC, Brighton T, Chesterman CN. Plasma P-selectin is increased in thrombotic consumptive platelet disorders. Blood 1994;83:1535-41.

14. Rickles FR, Levine MN, Dvorak HF. Abnormalities of hemostasis in malignancy. In: Colman RW, Hirsh J, Marder VJ, Clowes AW, George JN, eds. Hemostasis and thrombosis: basic principles and clinical practice, 4th ed. Philadelphia: Lippincott Williams \& Wilkins, 2001. 1131-52.

15. Roselli M, Mineo TC, Basili S, Mariotti S, Martini F, Bellotti A Ambrogi V, Spila A, D’Alessandro R, Gazzaniga PP, Guadagni F, Ferroni P. Vascular endothelial growth factor (VEGF-A) plasma levels in non-small cell lung cancer: relationship with coagulation and platelet activation markers. Thromb Haemost 2003;89:177-84.

16. Roselli M, Guadagni F, Martini F, Spila A, Mariotti S, D’Alessandro R, Aloe S, Gazzaniga PP, Basili S, Cosimelli M, Ferroni P. Association between serum carcinoembryonic antigen and endothelial cel adhesion molecules in colorectal cancer. Oncology 2003;65:132-8.

17. Iversen LH, Thorlacius-Ussing O. Systemic coagulation reactivation in recurrence of colorectal cancer. Thromb Haemost 2003;89:726-34.

18. Honn KV, Tang DG, Chen YQ. Platelets and cancer metastasis: more than an epiphenomenon. Semin Thromb Hemost 1992;18:392-415.

19. Roselli M, Mineo TC, Basili S, Martini F, Mariotti S, Aloe S, Del Monte G, Ambrogi V, Spila A, Palmirotta R, D'Alessandro R, Davì $\mathrm{G}$, et al. Soluble CD40 ligand (sCD40L) plasma levels in lung cancer. Clin Cancer Res 2004;10:610-4.

20. Gangopadhyay A, Bajenova O, Kelly TM, Thomas P. Carcinoembryonic antigen induces cytokine expression in Kuppfer cells: implications for hepatic metastasis from colorectal cancer. Cancer Res 1996; 56:4805-10.

21. Gangopadhyay A, Lazure DA, Thomas P. Adhesion of colorectal carcinoma cells to the endothelium is mediated by cytokines from CEA stimulated Kupffer cells. Clin Exp Metastasis 1998;16:703-12.

22. Lee AY. Cancer and thromboembolic disease: pathogenic mechanisms. Cancer Treat Rev 2002;28:137-40.

23. Minami S, Furui J, Kanematsu T. Role of carcinoembryonic antigen in the progression of colon cancer cells that express carbohydrate antigen. Cancer Res 2001;61:2732-5. 